\title{
De cuerpos presentes: participación política de las mujeres e interrupción voluntaria del embarazo -IVE-
}

\author{
Bodies present: political participation of women \\ and voluntary interruption of pregnancy -IVP-
}

Dos corpos presentes: participação politica das mulberes e interrupção voluntária da gravidez -IVGDes corps présents: participation politique des femmes et interruption volontaire de grossesse -IVG存在的机构中:妇女的政治参与和白愿中断怀孕

\author{
María Julieta Cena ${ }^{1}$ y Marina Villarreal ${ }^{2}$ \\ Universidad Nacional de Córdoba, Argentina
}

Revista Derechos en Acción ISSN 2525-1678/ e-ISSN 2525-1686

Año 6/Nº 19 Otoño 2021 (21 marzo a 20 junio), 147-183

DOI: https://doi.org/10.24215/25251678e513

Recibido: 01/04/2021

Aprobado: 15/05/2021

Resumen: El presente artículo analiza el impacto de la presencia de las mujeres como diputadas y senadoras en el Congreso Nacional Argentino en relación al tratamiento y votación del proyecto de legalización de la interrupción voluntaria del embarazo en el año 2018, la Ley 27610 en el

\footnotetext{
1 Abogada. Magister en Derecho y Argumentación (UNC). Becaria doctoral de CONICET. Centro de Investigaciones Jurídicas y Sociales - CONICET - Facultad de Derecho y Ciencias Sociales - Universidad Nacional de Córdoba. Email: mjulietacena@gmail.com (ORCID: https://orcid.org/0000-0003-4333-1451).

2 Abogada. Master en Derecho Constitucional (CEPC-UIMP). Becaria doctoral de CONICET. Centro de Investigaciones Jurídicas y Sociales - CONICET - Facultad de Derecho y Ciencias Sociales - Universidad Nacional de Córdoba. Email: marianavillarrealz@gmail.com (https://orcid.org/0000-0003-4934-8481).
} 
2020 y su vinculación con la aplicación de Ley 27412 de “Paridad de Género en Ámbitos de Representación Política". Para ello, desde un enfoque de género, se revisa las dinámicas de exclusión de las mujeres en la participación política representativa y el fundamento de las acciones afirmativas (como el cupo y la regla de paridad), para luego exponer su relación con el proceso de ampliación de derechos de las mujeres. Sin desconocer la trascendencia del contexto social y los millares de personas que pugnaron de cuerpo presente en las calles, el proceso de sanción de la ley 27610 constituye una oportunidad única para reflexionar sobre la justificación de las acciones positivas para garantizar la presencia de las mujeres en los órganos representativos, remediar su exclusión histórica y mejorar así la calidad democrática.

Palabras clave: acciones afirmativas, democracia paritaria, aborto.

Abstract: This article analyzes the impact of the presence of women as deputies and senators in the Argentine National Congress in relation to the treatment and voting of the project to legalize the voluntary interruption of pregnancy in 2018, Law 27610 in 2020 and its link with the application of Law 27412 on "Gender Parity in Spheres of Political Representation". To do this, from a gender perspective, the dynamics of exclusion of women in representative political participation and the basis of affirmative actions (such as the quota and the parity rule) are reviewed, to then expose their relationship with the process of expansion of women's rights. Without ignoring the importance of the social context and the thousands of people who struggled to be present in the streets, the process of enactment of Law 27610 constitutes a unique opportunity to reflect on the justification of positive actions to guarantee the presence of women in representative bodies, remedy their historical exclusion and thus improve the quality of democracy.

Keywords: affirmative actions, parity democracy, abortion.

Resumo: Este artigo analisa o impacto da presença de mulheres como deputadas e senadoras no Congresso Nacional Argentino em relação ao tratamento e votação do projeto de legalização da interrupção voluntária da gravidez em 2018, Lei 27.610 em 2020 e sua vinculação com a aplicação da Lei 27412 sobre "Paridade de Gênero nas Esferas de Representação Política". Para isso, a partir de uma perspectiva de gênero, são revistas as dinâmicas de exclusão das mulheres na participação política 
representativa e as bases das ações afirmativas (como a cota e a regra da paridade), para então expor sua relação com o processo de expansão das mulheres. direitos. Sem deixar de lado a importância do contexto social e dos milhares de pessoas que lutaram para estar nas ruas, o processo de sanção da lei 27.610 constitui uma oportunidade única para refletir sobre a justificativa de ações positivas para garantir a presença das mulheres nos órgãos representativos, remediar sua exclusão histórica e, assim, melhorar a qualidade da democracia.

Palavras-chave: ações afirmativas, democracia paritária, aborto.

Résumé: Cet article analyse l'impact de la présence des femmes en tant que députées et sénatrices au Congrès national argentin en relation avec le traitement et le vote du projet de légalisation de l'interruption volontaire de grossesse en 2018, la loi 27610 en 2020 et son lien avec l'application de Loi 27412 sur «la parité entre les sexes dans les domaines de la représentation politique». Pour ce faire, dans une perspective de genre, la dynamique d'exclusion des femmes dans la participation politique représentative et la base des actions positives (comme le quota et la règle de parité) sont revues, pour ensuite exposer leur relation avec le processus d'expansion des femmes. droits. Sans ignorer l'importance du contexte social et des milliers de personnes qui ont lutté pour être présentes dans les rues, le processus de sanction de la loi 27610 constitue une occasion unique de réfléchir sur la justification des actions positives pour garantir la présence des femmes dans les instances représentatives, remédient à leur exclusion historique et améliorent ainsi la qualité de la démocratie.

Mot-clés: actions positives, démocratie paritaire, avortement.

摘要：本文分析了阿根廷人大代表中女性代表和参议员的影响对 2018年自愿中断妊娠合法化项目的治疗和投票. 2020年第27610号 法律及其与实施的联系关于 “政治代表领域的性别均等”的第 27412 号法律为此从性别观点出发回顾了在代表政治参与中排斥妇女的动 态以及平权行动的基础例如配额和均等规则, 从而揭示了她们与妇 女扩张进程的关系权利在不忽略社会环境的重要性以及努力挣扎在 街头的数千人的情况下第 27610 号法律的制裁程序提供了一个独特 的机会可以反思采取积极行动的理由以确保妇女在代表机构中的存 在纠正他们的历史排斥从而提高民主质量.

关键字: 平权行动, 平等民主, 坆胎 


\section{Introducción}

El 2020 culminó con uno de los hechos políticos más trascendentes para la historia de lucha del movimiento feminista en Argentina: la sanción de la Ley $27610^{3}$ que garantiza a las mujeres y otras personas con capacidad de gestar, el derecho a decidir la interrupción voluntaria del embarazo (en adelante IVE) hasta la semana 14 del proceso gestacional. Este triunfo, que hoy es referencia a lo largo del continente latinoamericano, puede ser comprendido como el resultado directo de un proceso iniciado hace más de 30 años a partir de los Encuentros Nacionales de Mujeres, la Campaña Nacional por el Derecho al Aborto Seguro, Legal y Gratuito (conformada en el año 2005) y la ampliación del movimiento feminista a partir del "Ni Una Menos" desde el 2015 ${ }^{4}$. En este sentido, como sostiene Bergallo $(2021)^{5}$, la ley es producto de un proceso de legitimidad democrática inédito desde el punto de vista de la extensión de la deliberación, la especificación de los mandatos de representación y la participación ciudadana.

En este contexto, el estudio del debate y la votación sobre la ley de IVE demuestra la importancia de garantizar la participación política de las mujeres ${ }^{6}$ y otros colectivos como integrantes

3 CONGRESO DE LA NACIÓN ARGENTINA (30/12/2020). Ley de Acceso a la interrupción voluntaria del embarazo [Ley 27610 de 2020].

4 Para más información sobre el proceso, véase ECONOMÍA FEMINISTA (2019) "La innovación política desde los feminismos". Disponible en: https://economiafeminita.com/ la-innovacion-politica-desde-los-feminismos/

5 BERGALLO,Paola(2021). “Simposio «El aborto legal en América Latina» Parte VI: Un nuevo paso en la constitucionalización de la ciudadanía sexual en Argentina" en Ibericonnet Blog. Disponible en: https://www.ibericonnect.blog/2021/01/simposio-el-aborto-legal-en-america-latinaparte-vi-un-nuevo-paso-en-la-constitucionalizacion-de-la-ciudadania-sexual-en-argentina/

6 En este artículo nos referiremos a las mujeres como categoría jurídica que engloba la identificación y representación de las mujeres cis género, como colectivo que comparte una experiencia común de discriminación de hecho y de derecho. Sin embargo, no queremos dejar de advertir que esta es solo una acepción posible, toda vez que se trata un colectivo no homogéneo que nuclea diversidad de identidades, razas, clase entre otras. De la misma forma, es necesario resaltar que la problemática de la discriminación por razones de género 
del cuerpo colegiado que tiene la función de expresar en las leyes la "voluntad general". Es que la ausencia o escasa participación política de las mujeres, puede constituir una pérdida tanto para quienes nos identificamos en dicho colectivo, como también para la calidad democrática y, por ende, para toda la sociedad. En este sentido, el proceso de sanción de esta ley constituye una oportunidad única para reflexionar sobre la justificación de las acciones positivas como el cupo, para garantizar su presencia y remediar la exclusión histórica.

El presente trabajo parte de analizar las dinámicas de exclusión de las mujeres en la participación política representativa, así como las acciones afirmativas que tienden a una igualdad real de oportunidades, para observar su impacto en el proceso de legalización de las IVE. Sin desconocer la trascendencia del contexto social y las millares de personas que pugnaron de cuerpo presente en las calles, revisaremos el proceso de sanción de la ley 27610 (2020), para reflexionar sobre el rol de las mujeres y varones que les tocó estar ocupando "la banca" en ese momento histórico, en virtud de las normativas que garantiza la paridad participativa.

\section{II. ¿Y las mujeres dónde están? La distinción entre lo público y lo privado y su relación con la participación política de las mujeres}

Parece inverosímil la coexistencia de un discurso liberal que pregonaba una pretensa igualdad universal y la negación de la participación política de las mujeres. Sin embargo, recién a mitad del siglo XX y luego de muchos años de lucha, las mujeres logramos obtener el derecho a votar y ser elegidas, derecho que los hombres gozaban desde mucho tiempo atrás ${ }^{7}$.

\footnotetext{
en la política y sociedad excede esta categoría e incluye a otras identidades sexo genéricas. Si bien por cuestiones de brevedad no nos adentraremos en los debates sobre el alcance del sujeto político de los feminismos, recomendamos a tales fines la lectura de DORLIN, E. (2009). Sexo, género y sexualidades. Introducción a la teoría feminista. Buenos Aires: Nueva Visión.

7 En Argentina hubo que esperar hasta el año 1947, para que la Cámara de Diputados de la Nación convierta en ley el voto femenino. Es importante reconocer que este hito es el
} 
Aunque hoy no existen restricciones legales, basta mirar quiénes ocupan cargos de poder político ${ }^{8}$ para advertir que las desigualdades en base al género persisten, con los costos que implica para la legitimidad democrática la escasa representatividad de las mujeres y otras identidades. Es que, si bien en principio todos/as los ciudadanos y ciudadanas podemos elegir, ser elegidos/as y ocupar puestos de poder, lo cierto es que las barreras a las que nos enfrentamos las mujeres son invisibles y van más allá de nuestra voluntad. Son consecuencia de una estructura que sistemáticamente ha performateado 9 nuestras prácticas, decisiones y posibilidades de vida en torno a una jerarquía sexo-genérica. Es por eso que, en estos contextos, tratar a todas las personas por igual no garantiza la igualdad real y resultan necesarias otros tipos de políticas.

Los estudios de género (Pateman, 1996 ${ }^{10}$; Ciriza, 2001 ${ }^{11}$; Olsen, $1999^{12}$; entre otras) nos permiten comprender la manera

resultado de un proceso internacional promovido por el movimiento sufragista que tiene su correlato en Argentina a partir 1911. Desde ese año y hasta 1939 se presentaron distintas iniciativas que buscaron garantizar el voto femenino, pero muchas de ellas ni siquiera se debatieron en el recinto.

8 De acuerdo a ONU Mujeres (2019) a febrero del año 2019, solo un 24,3\% de las bancas parlamentarias mundiales eran ocupadas por mujeres. Véase: ONU Mujeres (2019) “Mujeres en la política" Disponible en: https://www.unwomen.org/-/media/headquarters/attachments/ sections/library/publications/2019/women-in-politics-2019-map-es.pdf?la=es\&vs=3303

9 Siguiendo a Butler la noción de performatividad utilizada, refiere a la tecnología del poder en la construcción de las subjetividades. Para un análisis general de la noción de performatividad como categoría teórica en los trabajos en el pensamiento de Judith Butler, recomendamos la lectura de SAXE, Facundo (2015). "La noción de performatividad en el pensamiento de Judith Butler: queerness, precariedad y sus proyecciones." Estudios Avanzados (24). Disponible en: https://www.redalyc.org/jatsRepo/4355/435543383002/html/index.html

10 PATEMAN, Carole (1996). “Críticas feministas a la dicotomía público/privado" en C. Castells, Perspectivas feministas en la teoría política (págs. 31-52). Editorial Paidos Ibérica, Barcelona.

11 CIRIZA, Alejandra (2001). “Democracia y ciudadanía de mujeres: encrucijadas teóricas y políticas" en Teoría y filosofía política. La recuperación de los clásicos en el debate (págs. 159-174). Buenos Aires: Clacso. Recuperado el 2021 de 01 de 15, de http://bibliotecavirtual. clacso.org.ar/clacso/se/20100613045003/12ciriza.pdf

12 OLSEN, Frances (1999). El mito de la intervención del Estado en la Familia. En A. Facio, \& L. Fries, Género y Derecho (págs. 268-288). LOM, Santiago de Chile. 
en que la distinción ideológica entre los ámbitos públicos y privados, en la que se basa el Estado liberal, opera a favor a la institucionalización del poder masculino sobre las mujeres. El diseño institucional escinde la sociedad política, donde se expresan los intereses públicos y la sociedad civil, donde las reglas son la intimidad, los intereses particulares y la no intromisión estatal.

Esta distinción entre espacios públicos y privados está sexuada y jerarquizada (Pateman, 1996) ${ }^{13}$ y resulta necesaria y funcional para la "división sexual del trabajo" que emerge con el desarrollo del sistema capitalista. De esta manera, en el sistema capitalista heteropatriarcal, la familia nuclear surge como la estructura social organizada en torno a la división de las tareas pertinentes a la producción. Dentro de ella, se atribuye a los varones la labor de ganar el sustento familiar y representar a la familia en el espacio público, mientras a las mujeres se nos encarga la tarea de gestionar (en privado) el cuidado y las situaciones de dependencia de los miembros de la familia (Rodriguez Ruiz, 2011) ${ }^{14}$. Las extensas jornadas que requieren el trabajo asalariado o la actividad política de los hombres se nutren de la existencia de mujeres ocupadas en las tareas domésticas y de cuidado. De esta forma se invisibiliza que el ejercicio de los valores que presupone el liberalismo, como libertad, independencia, e igualdad dependen en la práctica que las personas puedan cultivar, en el ámbito privado, sus capacidades, desarrollarlas y expresarse, como presupuesto material, emocional y psicológico de su participación libre.

La inclusión de las mujeres en el ámbito público durante el siglo XX no llevó a una redistribución equitativa de las

13 PATEMAN, Carole (1996). Críticas feministas a la dicotomía público/privado. En C. Castells, Perspectivas feministas en la teoría política (págs. 31-52). Editorial Paidos Ibérica, Barcelona.

14 RODRIGUEZ RUIZ, Blanca (2011). “Matrimonio, género y familia en la Constitución española: trascendiendo la familia nuclear" en Revista española de derecho constitucional, 69-102. 
tareas domésticas, por el contrario, quienes realizan trabajos fuera de su hogar, suelen cumplir con dos jornadas: la formal y la doméstica ${ }^{15}$. En este sentido, reflexionando sobre las posibilidades reales de las mujeres para acceder a otros espacios, Pateman (1990) ${ }^{16}$ se pregunta: “...(¿) por qué aquellas personas que ya cargan con el peso de dos trabajos, querrían aceptar más responsabilidades y aprovechar las oportunidades que les traería la democratización (?)” (pág. 18).

El excepcional acceso de las mujeres a las posiciones de poder, muestra un supuesto "mundo de posibilidades" a la vez que oculta las barreras que necesitamos enfrentar para llegar a esa meta. De esta manera, nuestras subjetividades se moldean bajo la ilusión de una meritocracia engañosa a la que debemos aspirar, sin dar cuenta que su alcance no depende simplemente de nuestra voluntad o esfuerzo. En otras palabras, las mujeres que consiguen acceder a ciertos puestos de poder, son presentadas como las referentes de lo posible, haciendo pesar sobre quienes no lo logran, la responsabilidad individual de no haber alcanzado la meta, y no sobre las estructuras que sostienen las barreras.

A pesar de los cambios producidos con la incorporación de las mujeres a espacios públicos, el contexto social continúa siendo hostil para la intervención política de las mujeres

\footnotetext{
15 En el año 2013 se realizó en Argentina la primera Encuesta sobre Trabajo No Remunerado y Uso del Tiempo por parte del Instituto Nacional de Estadísticas y Censos. Los datos revelaron que las mujeres, sin distinción de estado civil, dedican en promedio una cantidad de horas muy superior al trabajo no remunerado que los hombres, aun cuando se encuentren participando activamente en el mercado laboral. En promedio las mujeres dedican 6 horas por días al trabajo doméstico no remunerado mientras que los hombres solo 2. Del estudio también se desprende que los hombres que realizan mayor cantidad de trabajo doméstico son aquellos separados o divorciados $(70,4 \%)$ mientras que las mujeres que más toman a su cargo esas tareas son aquellas en relación de pareja estable (95,3\%). Véase el documento "Encuesta sobre Trabajo No Remunerado y uso del tiempo Resultados por jurisdicción". Disponible en línea: http://www.indec.mecon.ar/uploads/informesdeprensa/tnr_07_14.pdf.

16 PATEMAN, Carole (1990). Feminismo y Democracia. Debates Feministas. doi:https://doi. org/https://doi.org/10.22201/cieg.01889478p.1990.1.1848
} 
limitada por la opresión y la posición económica marginal. Rodríguez (1999) ${ }^{17}$ explica que, si bien se perciben cambios sociales, persisten las circunstancias psicológicas que dificultan la plena participación en espacios públicos: "las mujeres continúan sufriendo un sentimiento ambivalente con respecto al trabajo fuera de la casa, enfrentando la consternación y preocupación por eventuales fallas en lo profesional o en lo personal" (Rodríguez, 1999, pág. 260) . Otro obstáculo al que nos enfrentamos las mujeres como grupo, es que la medida de la capacidad y competencia es expresada en virtud de las experiencias, valores y prejuicios de los varones. Como bien señala Rodríguez (1999) la predominancia de varones en roles de poder social, también responde a que estos:

han recibido una educación y un entrenamiento que ha inspirado en ellos actitudes y cualidades, así como conocimientos y habilidades que los proveen de mejores herramientas para superar a las mujeres en aquellas actividades que, por haber sido ejercidas casi exclusivamente por varones, privilegian la posesión de estas características (pág. 276)

La asimetría estructural entre varones y mujeres, se refleja en la construcción de la identidad. En una matriz heteropatriarcal, los varones crecen, en general, con la confianza de ser plenamente aceptados como miembros respetados de la sociedad y con derechos y privilegios que les posiciona en un escalón superior en comparación con las otras identidades sexo genéricas. Por el contrario, las mujeres debemos demostrar altos grados de perfección para el acceso y el reconocimiento social en ámbitos por fuera de los domésticos.

Además, la ausencia de mujeres en las esferas públicas opera como "la profecía autocumplida", desmotivando la intervención de otras personas que se enfrenta a la falta de modelos

17 RODRIGUEZ, Marcela (1999). "Igualdad, democracia y acciones positivas" en A. Facio, \& L. Fries, Género y Derecho. LOM, Santiago de Chile. 
en esos roles. De esta forma, la escasa participación desalienta la participación, en tanto que las mujeres somos consideradas ocupando el lugar de una minoría aislada, siempre en exhibición, examinadas y cuestionadas (Rodríguez, 1999) ${ }^{18}$.

\section{Del cupo a la paridad: reseña de una transición y su impacto en la agenda legislativa}

Como resultado de los obstáculos señalados, históricamente en el mundo y en particular en América Latina, las mujeres hemos tenido una escasa participación formal en los escenarios políticos. Ofrecer igualdad de trato a las mujeres y otras identidades, sólo perpetúa la situación de exclusión de ciertos ámbitos de poder. Frente a este panorama, las acciones positivas se presentan como un mecanismo indispensable para revertir esta situación sostenida por su propia inercia. Estas medidas implican el reconocimiento de ciertas prerrogativas o trato diferencial de ciertos grupos por su pertenencia, con la finalidad de equiparar los puntos de partida y la reducción de las consecuencias de la discriminación estructural. Lo expuesto se enmarca en la comprensión de que, si el punto de partida es asimétrico, las aplicaciones de reglas neutrales conducen a resultados desiguales.

Si bien en Argentina las mujeres conquistamos el derecho al sufragio en el año 1947, la necesidad de implementar políticas de acción positiva se reflejaba en los bajos porcentajes de participación de las mujeres en cargos electivos. Por eso, en el año 1991 se dicta la Ley N. ${ }^{\circ} 24012^{19}$ por la cual se obligaba a los partidos políticos a incorporar un 30\% de mujeres a las listas para elecciones legislativas nacionales. Esta se conoció como la "ley de cupo" y se convirtió en la primera de este tipo en América Latina. Gracias a la introducción de estos mecanismos, a partir

\footnotetext{
18 RODRIGUEZ, Marcela, ob.cit

19 CONGRESO DE LA NACIÓN ARGENTINA (06/11/1991) "Ley de cupo femenino" [Ley NN24012 de 1991], Buenos Aires.
} 
de la década de los '90 la región latinoamericana presenta un crecimiento de la intervención de mujeres, principalmente, en los estamentos parlamentarios (Freidenberg \& Lajas García, 2015) ${ }^{20}$.

Acciones afirmativas como el cupo, fueron expresamente receptadas por la reforma constitucional del año 1994 al incorporar el art. 75 inc. 23 que establece la obligación del Congreso de la Nación de " legislar y promover medidas de acción positivas que garanticen la igualdad real de oportunidades y de trato, y el pleno goce y ejercicio de los derechos reconocidos por esta Constitución y por los tratados internacionales vigentes a las mujeres [...]" (entre otros colectivos históricamente desprotegidos). De esta forma, la Constitución Nacional Argentina da por zanjada la discusión normativa sobre la procedencia de este tipo de acciones.

Por su parte, la Convención para la Eliminación de toda forma de discriminación contra la mujer (en adelante CEDAW) que en Argentina goza de jerarquía constitucional ${ }^{21}$, refuerza la obligación del Estados de tomar medidas de acción positivas para la obtención de igualdad real de oportunidades ${ }^{22}$. La expresión "igualdad real", en tanto fundamento de las acciones positivas, debe ser entendida como un tipo de igualdad que atiende al contexto social y que aspira a modificar e igualar el impacto de la estructura social sobre las oportunidades de las personas (Grosman, 2008) ${ }^{23}$.

20 FREIDENBERG, Flavia y LAJAS GARCÍA, Sara (2015). De la cuota a la paridad: Ias reformas para mejorar la representación política de las mujeres en América Latina. Proyecto de Reformas Políticas en América Latina (1978-2015). (S. d. Americanos, Ed.) Washintong D.C. Disponible en https://reformaspoliticas.org/wp-content/uploads/2019/09/DT-11.pdf

21 En la reforma constitucional de 1994, a través de su artículo 75 inc. 22, se reconoce jerarquía constitucional a ciertos tratados y convenciones internacionales sobre derechos humanos firmados por Argentina, incorporándolos al marco jurídico nacional con la máxima jerarquía, entre ellos la CEDAW que, por lo tanto, integra el bloque constitucional y resulta directamente aplicable y exigible judicialmente.

22 Véase Art. 4 y 7 de CEDAW y la Recomendación № 25 del Comité CEDAW (1999)

23 GROSMAN, Lucas (2008). La igualdad estructural de oportunidades en la Constitución Argentina. Buenos Aires. Disponible en: https://www.palermo.edu/derecho/publicaciones/ inv_jurid/igualdad_estructural.pdf 
Si bien el diseño e implementación de la mencionada ley de cupo favoreció el acceso de las mujeres a las candidaturas partidarias y a cargos de representación popular, prontamente encontró barreras para cumplir plenamente su cometido. En primer lugar, la resistencia al cambio se manifestó mediante acciones meramente formales por parte de los partidos políticos (por ejemplo: presentar como candidatas a mujeres que finalmente no asumían) y la concentración de varones en las cabezas de listas, lo que perpetuaba con la sobrerrepresentación masculina (Del Cogliano \& Degiustti, 2018) ${ }^{24}$.

Asimismo, los obstáculos socioculturales relativos a las tareas de cuidado y la división sexo genérica de las profesiones, continuaron limitando las posibilidades de transformación deseada. El informe sobre trayectorias políticas de mujeres y varones en las legislaturas argentinas realizado por el Equipo Latinoamericano de Justicia (2011) ${ }^{25}$, a 20 años de las leyes de cupo, da cuenta de las dificultades que generalmente encuentran las mujeres para compatibilizar sus actividades públicas con las del ámbito privado. En efecto, la proporción de mujeres legisladoras solteras es tres veces mayor a la de los varones legisladores, así como también es mayor la cantidad de mujeres sin hijos/as que ocupan bancas legislativas, a comparación de la cantidad de varones sin hijos/as. Estos datos indican que, a mayor nivel de responsabilidades familiares, las mujeres tienen menores probabilidades de aspirar a una carrera legislativa que sus pares varones. La investigación concluye que las mujeres se encuentran todavía excluidas de los cargos de liderazgo y conducción, aun cuando éstas cuentan con experiencia laboral y con credenciales educativas superiores a las de los varones (pág.10).

\footnotetext{
24 DEL COGLIANO Natalia y DEGIUSTTI Dario (2018). La nueva Ley de Paridad de Género en Argentina: antecedentes y desafíos. Observatorio Político Electoral. Disponible en https:// www.argentina.gob.ar/sites/default/files/ope-doc1-paridad.pdf

25 EQUIPO LATINOAMERICANO DE JUSTICIA Y GÉNERO. (2011). Detrás del Número: Un estudio sobre las trayectorias políticas de mujeres y varones en las legislaturas argentinas. Disponible en http://www.ela.org.ar/a2/objetos/adjunto.cfm?aplicacion=APP187\&cnl=15\&opc=49\&codcontenido $=660 \&$ codcampo $=20$
} 
Circunstancias como las descriptas determinaron que el cupo mínimo, en la práctica, funcionara como un techo por lo cual se presentó como necesario realizar reformas. Es así como, en el año 2017, Argentina sancionó la Ley No $27412^{26}$ que modificó el Código Electoral Nacional a los fines de incorporar la paridad de género en ámbitos de representación política, más precisamente en la órbita parlamentaria. La ley dispone que las listas de candidatos/as que se presenten para la elección de senadores/as y diputados/as nacionales y parlamentarios/as del Mercosur deben integrarse intercalando a mujeres y varones, desde el/la primer/a candidato/a titular hasta el/la último/a candidato/a suplente.

De esta manera se consolida el camino hacia un modelo de democracia paritaria como estrategia para desandar la histórica subordinación social de las mujeres. En ese sentido, en el Consenso de Quito producto de la Décima Conferencia Regional sobre la Mujer en América Latina y el Caribe $(2007)^{27}$ se sostuvo que la paridad es:

[...] uno de los propulsores determinantes de la democracia, cuyo fin es alcanzar la igualdad en el ejercicio del poder, en la toma de decisiones, en los mecanismos de participación y representación social y política, y en las relaciones familiares al interior de los diversos tipos de familias, las relaciones sociales, económicas, políticas y culturales, y que constituye una meta para erradicar la exclusión estructural de las mujeres (punto 17)

\section{Más mujeres en el Congreso ¿mejor democracia?}

La importancia de la incorporación de las mujeres en la representación política va más allá de la justicia intrínseca que implica igualar oportunidades entre hombres y mujeres; se

26 CONGRESO DE LA NACIÓN ARGENTINA (22/11/2017) Ley de paridad de género en ámbitos de representación política [Ley Nº 27412 de 2017].

27 CEPAL (2007) Décima Conferencia Regional sobre la Mujer de América Latina y el Caribe: Consenso de Quito. Disponible en: https://www.cepal.org/prensa/noticias/comunicados/0/29450/ DSC1-E-ConsensodeQuito-final.pdf 
vincula también con la justificación del régimen democrático. A grandes rasgos, desde una perspectiva clásica liberal, la democracia se justifica porque es la forma de asegurar en cierta medida el autogobierno. Esta ficción implica que las limitaciones a la autonomía de las personas, son legitimadas mediante un sistema representativo donde los/as gobernados/as eligen a quienes tomaran decisiones en su nombre.

Como explica Marcela Rodríguez (1999) ${ }^{28}$, desde este enfoque, las cuotas se justificarían en la medida que de lo contrario no existirían alternativas reales y viables para la elección de representantes. Por lo tanto, la ausencia de representantes mujeres en el proceso de deliberación y sanción de normas debilitaría la afirmación de que estas han sido consentidas por las mujeres. Desde esta perspectiva, aunque un sistema de acción positiva como las cuotas.

no es una condición suficiente para garantizar el consentimiento pleno y libre de las mujeres, resulta si una condición necesaria su adopción, para que exista una verdadera alternativa de forma tal que ese consentimiento sea válido y para la participación real en la toma de decisiones (Rodríguez, 1999, pág. 281) ${ }^{29}$.

Por su parte, propuestas más recientes sobre la justificación de la democracia, como las distintas concepciones dialógicas, justifican el sistema democrático sobre las bases del valor de la discusión pública mediante procedimientos reglados para la toma de decisiones informadas y consensuadas. Más allá de las distintas variantes de las concepciones dialógicas, en líneas generales, estas propician una participación amplia en la discusión de las personas afectadas por las soluciones, para maximizar la probabilidad de que la solución arribada sea considerada válida. Así, sostiene Nino $(2005)^{30}$ que

\footnotetext{
28 RODRIGUEZ, Marcela, ob.cit.

29 RODRIGUEZ, Marcela, ob.cit.

30 NINO, Carlos (2005). Fundamentos de derecho constitucional. Editorial Astrea, Buenos Aires.
} 
Si asumimos como generalización empírica que nadie conoce mejor sus intereses que uno mismo, la aceptación por parte de todos los afectados de un cierto principio es un indicio muy firme de que responde a exigencias de imparcialidad. Por otra parte, también el diálogo maximiza la racionalidad y el conocimiento de los hechos, dada su virtualidad para que, en el curso de él, se pongan de manifiesto errores de razonamiento y deficiencias de información. (pág. 203- 4)

Desde este enfoque, la participación política paritaria de las mujeres, un grupo que representa el 50\% de la población, resulta consistente con los principios justificatorios de esta concepción de la democracia. Como dice Marcela Rodríguez (1999) ${ }^{31}$ :

Dado que nadie conoce mejor sus intereses que uno/a mismo/a, es muy improbable que los varones estén capacitados para representar los intereses de las mujeres. Sin la participación de mujeres en el debate y el proceso de toma de decisiones, inevitablemente se producirá una distorsión en la apreciación de sus intereses, debilitando las posibilidades del mecanismo democrático como espacio de acción colectiva tendiente a la imparcialidad. Esta distorsión se produce por la falta de explicitación clara de tales intereses, por la falta de conocimiento cierto de tales intereses por los representantes varones o por la interposición de los intereses propios de estos últimos (pág. 285).

En otras palabras, la propuesta de la democracia liberal, pone el acento en el momento del consentimiento que se expresa en la elección del representante para dar por zanjada la cuestión de la legitimidad, mientras que la propuesta dialógica se centra en los efectos que tendría la pluralidad de la "voces" dentro del debate democrático para la calidad de respuesta.

Sin embargo, ambas teorizaciones justificatorias surgen dentro del ámbito de lo especulativo, ya que es imposible afirmar

31 RODRIGUEZ, Marcela, ob.cit. 
con certeza que las mujeres electas responderán necesariamente a los intereses de las mujeres representadas que, por otro lado, resulta difícil de determinar siendo un colectivo por demás heterogéneo. En este sentido, las mujeres, como cualquier otro grupo, no vivimos iguales experiencias, sino que estamos atravesadas por nuestra clase, formación, raza, edad, etc. Además, no se puede sostener que tanto la elección como el posterior ejercicio del poder responda directamente al grupo, cuando el sistema electoral permite elegir a representantes en base a una propuesta de gobierno presentada por partidos políticos. De la misma manera, es plausible que los varones también se encuentren comprometidos con la agenda de género.

Más allá de eso, lo cierto es que la práctica nos muestra que el aumento de la cantidad de mujeres en bancas legislativas efectivamente potenció el ingreso al debate público, de miradas y problemáticas propias de la experiencia social de las mujeres. Por ejemplo, el $79 \%$ de los proyectos sobre cuotas de género presentados entre los años 1989 y 2007, así como el 80\% de las iniciativas sobre despenalización/ legalización del aborto, acceso a la contracepción y derechos reproductivos, y el 69\% de las propuestas en materia de violencia de género, fueron introducidas por legisladoras mujeres (Franceschet \& Piscopo, 2008) $)^{32}$. De igual forma, entre los años 1994 y 2003, 87 de las 177 diputadas nacionales que ocuparon su banca presentaron proyectos sobre temas de género (Archenti \& Johnson, 2006) ${ }^{33}$.

Además de la presentación de proyectos, el trabajo de las legisladoras nacionales ha sido fundamental para la aprobación de diversas leyes vinculadas a los derechos de las mujeres. Entre

\footnotetext{
32 FRANCESCHET Susan y PISCOPO Jennifer (2008). Gender quotas and women's substantive representation: Lessons from Argentina. Politics \& Gender, 4(3), 393-425. Disponible en: http:// www.web.pdx.edu/ mev/pdf/PS\%20471\%20Winter15\%20Readings/Franceschet_Piscopo.pdf 33 ARCHENTI Nelida \& JOHNSON Niki (2006). Engendering the legislative agenda with and without the quota. Revista Sociología, Problemas e Práticas(52). Disponible en: https://www. researchgate.net/publication/281295121_Engendering_the_legislative_agenda_with_and_ without_the_quota_A_comparative_study_of_Argentina_and_Uruguay
} 
ellas se pueden mencionar: la ley de Cupo Sindical Femenino (Ley 25674 del año 2002), Salud Sexual y Procreación Responsable (Ley 25673 del año 2002), Contracepción Quirúrgica (Ley 26130 del año 2006), y Protección integral para Prevenir, Sancionar y Erradicar la Violencia contra las Mujeres (Ley 26485 del año 2009) entre otras. Así, la incorporación de las mujeres en el Congreso de la Nación ha tenido como efecto tensionar las fronteras entre lo público y lo privado, mediante el planteamiento en la arena política de cuestiones históricamente reservadas al ámbito "de lo doméstico" o "privado" como la violencia, y recientemente la IVE.

\section{El camino hacia la paridad: los cambios en la conformación del Congreso a partir de la Ley 27412}

En el presente apartado analizaremos el impacto de la aplicación de la Ley de Paridad en la composición de las cámaras en relación al tratamiento del primer proyecto de IVE sometido a votación en el país en el año $2018^{34}$ y el proyecto que finalmente se convirtió en ley en el año 2020. Como mencionamos anteriormente, en el año 2017, Argentina sancionó la Ley $\mathrm{N}^{\mathrm{o}} 27412$, conocida como "ley de paridad". Sin embargo, estas nuevas disposiciones recién pudieron ser aplicada por primera vez en las elecciones legislativas del año 2019, toda vez que el poder legislativo argentino tiene un proceso complejo de constitución y elección, con disímil efecto según la Cámara que sea: Diputados y Senadores responden a distintas correlaciones de poder en el diseño institucional argentino.

La Cámara de Diputados cumple una intención de "representar al pueblo" y por consiguiente, se integra en función de un

\footnotetext{
34 En el año 2018 la Campaña Nacional por el Aborto Seguro, Legal y Gratuito presentó por séptima vez en el Congreso de la Nación un proyecto de ley para legalizar la IVE. Hasta entonces, ningún proyecto había llegado a ser debatido en comisiones o en el recinto. El proyecto de ley que finalmente fue debatido lleva el código: 0230-D-2018. Texto disponible en: https://www.hcdn.gob.ar/proyectos/textoCompleto.jsp?exp=0230-D-2018\&tipo=LEY.
} 
numero proporcional de diputados/as por cantidad de habitantes de los distintos distritos ${ }^{35}$ y duran en su mandato 4 años. En virtud de la Ley $22.847(1983)^{36}$ se estableció un porcentaje de 1 diputado/a cada 161000 habitantes de las 23 provincias y la Ciudad Autónoma de Buenos Aires (CABA), con un mínimo de $5^{37}$. La renovación de la Cámara de Diputados, no se produce de manera total en un único acto. Al contrario, cada jurisdicción renueva la mitad de sus diputados/as cada dos años. En la actualidad está conformada por 257 diputados y diputadas representantes de las 24 jurisdicciones, siendo las últimas elecciones del año 2019.

Atento que la ley N. 27412 de paridad de género, fue sancionada con posterioridad a la conformación de listas de las elecciones legislativas del año 2017, recién fue aplicada en las elecciones del año 2019. Por eso, en virtud del sistema de renovación de las bancas, aún no se ha podido observar plenamente sus resultados.

Más allá de esto, y adentrándonos en el proceso de legalización de las IVE, cabe resaltar que, en el año 2018, en oportunidad de tratarse el primer proyecto de ley de $\mathrm{IVE}^{38}$, la Cámara de Diputados estaba conformada por un total de 99 diputadas mujeres y 158 diputados varones, lo que significa que las mujeres ocupaban un $38,52 \%$ de las bancas con una amplia diferencia en relación a los varones que representaban el $61,47 \%$.

\footnotetext{
35 Con este término nos referirnos a las 23 provincias y la Ciudad Autónoma de Buenos Aires (CABA). Lo expuesto en tanto desde la reforma constitucional del año 1994, CABA tiene la misma representación en el Congreso que las 23 Provincias.

36 Decreto del presidente de facto Bignone (12/07/1983) "Ley de Convocatoria Electoral" [Decreto/Ley N 22.847 de 1983].

37 Actualmente 10 de las 24 jurisdicciones que tienen 5 diputados/as por ser el mínimo: Catamarca, Chubut, Formosa, La Pampa, La Rioja, Neuquén, Río Negro, San Luis, Santa Cruz y Tierra del Fuego.

38 PROYECTO DE LEY 0230-D-2018. Disponible en: https://www.hcdn.gob.ar/proyectos/ textoCompleto.jsp? exp=0230-D-2018\&tipo=LEY.
} 
En las elecciones del año 2019 se renovaron un total de 130 bancas que se distribuyeron ${ }^{39}$ entre 58 mujeres y 72 varones, lo que traduce en un $44,61 \%$ de las bancas disponibles cubiertas por mujeres, mientras que el $55,38 \%$ por varones. Es que, si bien la ley de paridad es obligatoria en la conformación de las listas, por el propio sistema de elección y designación de diputados/as, no necesariamente va a lograrse una paridad en la integración total del Congreso ${ }^{40}$.

En virtud de los reemplazos que se produjeron durante los años 2019 y 2020, en oportunidad de votarse la ley de IVE en el año 2020, la Cámara de Diputados estaba compuesta por 110 mujeres representando el $42,60 \%$ de la totalidad de la Cámara y 147 varones, que conforman el 57,19\% del recinto. Si comparamos con la conformación de la Cámara en la votación del proyecto de IVE en año 2018, es posible advertir una importante diferencia en la representación de las mujeres, quienes aumentamos la presencia política en 4 puntos, acercándose a la paridad en la Cámara de Diputados.

Distinto es el caso de Senadores. Es menester considerar que esta Cámara tiene desde su origen una intención conservadora y elitista. Basta recordar que la Constitución Nacional Argentina estipula como requisito para ocupar dicho cargo, la suma de cierta renta y que, si bien en la actualidad ha quedado en desuso, el artículo aún continúa con su histórica redacción ${ }^{41}$.

39 Cabe aclarar que esto no significa que sean personas que ingresaban por primera vez a las labores parlamentarias, ya que se da el caso de diputados y diputadas que renuevan su mandato, ya que la posibilidad de relección es ilimitada.

40 Para la distribución de las bancas entre los distintos partidos de forma proporcional a los votos se utiliza el Ilamado Sistema D’Hont. Cada agrupación presenta una lista de candidatos conforme a la cantidad de bancas que se ponen en juego en su distrito. Una vez finalizada la elección y realizado el recuento de votos, se excluyen todas las listas que no hayan superado el piso del $3 \%$ del padrón electoral del distrito. Luego se divide el total de los votos válidos obtenidos por las listas restantes por uno, dos, tres y así sucesivamente hasta llegar al número total de los cargos que se deben cubrir. Luego se ordenan los resultados de las divisiones de mayor a menor, ya que los cargos a repartir se asignarán a las mayores cifras.

41 Constitución Nacional Argentina, Art. 55: "Son requisitos para ser elegidos senador: tener la edad de treinta años, haber sido seis años ciudadano de la Nación, disfrutar de una 
Está integrada por la totalidad de 72 senadores/as que duran 6 años en ejercicio, correspondiendo 3 senadores/ras por jurisdicción, con independencia del número de habitantes. De esta manera, en el marco del sistema federal, se entiende que está Cámara representa la participación igualitaria de cada provincia y CABA en la toma de decisiones del gobierno central.

Por otra parte, la renovación de esta cámara tampoco se hace en forma total, sino de manera escalonada por tercios por conjuntos de provincias que van renovando sus bancas. A ello debe agregarse la particularidad que tiene en el sistema electoral, toda vez que, a partir de la reforma de 1994, se eligen dos senadores/as por la lista que mayor cantidad de votos obtuvo, mientras que la banca restante es asignada a la lista que le siguió en votos válidos emitidos.

Frente a estas particularidades, la ley de paridad de género ley $\mathrm{N}^{\circ} 27412$ además de la obligatoriedad de conformar con un $50 \%$ de mujeres ubicadas de manera alternada con varones, especificidades para los reemplazos. De esta manera prevé que para sustituir al/la senador/a de la lista que hubiere obtenido la mayoría de votos emitidos, se designará al/la senador/a siguiente del mismo sexo (Art. 3 de la Ley 27412 que modifica el Art.164 del Código Electoral Nacional) Siendo dos personas de distinto género las elegidas por la mayoría, con esa regla mantiene la paridad en caso de reemplazo ${ }^{42}$. En cambio, en el caso del senador o senadora electa por la minoría, la regla establece que el/la segundo/a titular de la lista de la segunda mayoría, será el/a primer/a suplente del Senador que por ella resultó elegido/a (Art. 2 de la Ley 27412 que modifica el Art.157 del Código Electoral Nacional). Por lo tanto, será una persona de otro género que cabeza de lista. Esta regla neutra favorece la

\footnotetext{
renta anual de dos mil pesos fuertes o de una entrada equivalente, y ser natural de la provincia que lo elija, o con dos años de residencia inmediata en ella."

42 Además, se establece que si no quedaran mujeres en la lista, se considerará la banca como vacante y será de aplicación el artículo 62 de la Constitución Nacional.
} 
incorporación de mujeres ya que la experiencia muestra que son los varones quienes siguen encabezando las listas. En este sentido, el Monitoreo de paridad en las elecciones de 2019 de ELA da cuenta que solo el $20 \%$ de los partidos llevaron a mujeres como su primera candidata ${ }^{43}$.

A pesar de la implementación de la ley de paridad, la conformación de la Cámara de Senadores entre los años 2018 y 2020, años en que se debatió la IVE; no varió demasiado en términos de género. De hecho, luego de las últimas elecciones legislativas del año 2019 las 42 bancas ocupadas por varones, aumentaron a 44, disminuyendo de 30 a 28 las mujeres en Senado. En otras palabras, en la votación del proyecto de ley IVE del año 2018 la Cámara de Senadores estaba compuesta por un $58,33 \%$ de varones frente a un $41,66 \%$ de mujeres. En cambio, en oportunidad de votarse la ley de IVE del año 2020, la Cámara poseía un total de $61,11 \%$ de varones y un $38,88 \%$ de mujeres.

Cómo surge a simple vista, esta primera aplicación de la ley de paridad de género no permitió cambiar la conformación en esta Cámara. Esto responde al diseño propio del sistema institucional y la conformación, casi en su totalidad, de las cabezas de lista por parte de varones. De las 24 bancas que se renovaron en el año 2019, 15 fueron ocupadas por varones, mientras que 9 por mujeres. Esto se debe a que, tanto la primera como la segunda mayoría de las listas de 7 de las 8 provincias que elegían, tenían a varones encabezando las listas. En consecuencia, salvo el caso de Neuquén, solo resultó electa senadora una mujer por cada provincia. El caso de Neuquén se presenta como excepcional, al ser la única jurisdicción que contaba con mujeres como candidatas primeras en las listas partidarias, motivo por el cual logró la elección de dos mujeres

43 Véase ELA (2019) Monitoreo Paridad Elecciones 2019 ¿Qué lugar ocupan las mujeres en las listas camino a las PASO?. Disponible en: http://www.ela.org.ar/a2/index.cfm?muestra\&codcontenido=4104\&plcontampl=12\&aplicacion=app187\&cnl=4\&opc=47 
como senadoras. Cabe destacar que ambas votaron a favor de la ley de IVE del año 2020.

A partir de dichas conformaciones, analizaremos el comportamiento de los votos frente al proyecto de IVE en relación al género de los/as legisladores/ras.

\section{Diputadas y senadoras en la sanción de la ley de IVE: actoras claves en la ampliación de la ciudadanía de las mujeres}

La ciudadanía de las mujeres en Argentina ha cobrado relevancia con el retorno de la democracia y la coyuntura internacional que establecieron nuevas regulaciones sobre los DDHH en general, y de las mujeres en particular. Sin embargo, como dice Alejandra Ciriza (2001) ${ }^{44}$ la ciudadanía reconocida por estos organismos internacionales encuentra su límite en las barreras invisibles interpuestas por un sistema heteropatriarcal capitalista. Vivimos en un mundo donde la ciudadanía aún está construida fundamentalmente sobre y por decisión de un solo cuerpo sexuado, el del varón. Sin embargo, los movimientos feministas y de la diversidad, avanzan en la lucha por la efectivización de los derechos y las transformaciones socio culturales para lograr una ciudadanía plena. En ese sentido, consideramos que la sanción de la IVE constituye uno de los logros más importantes para el avance de la ciudadanía de las mujeres y otras personas con capacidad de gestar en tanto implica el respeto de la dignidad, la igualdad y la autonomía.

El proceso que culmina con la sanción de esta ley debe ser leído como un triunfo de la política feminista en distintas instancias, formales e informales. Así, esta ley recoge la histórica demanda de las manifestaciones masivas a través de todo el

\footnotetext{
44 CIRIZA, Alejandra (2001). “Democracia y ciudadanía de mujeres: encrucijadas teóricas y políticas". En Teoría y filosofía política. La recuperación de los clásicos en el debate (págs. 159-174). Buenos Aires: Clacso. Recuperado el 2021 de 01 de 15, de http://bibliotecavirtual. clacso.org.ar/clacso/se/20100613045003/12ciriza.pdf
} 
país donde se alzaron los pañuelos verdes de la Campaña por el Aborto legal, seguro y gratuito que pusieron el tema en agenda y lograron la despenalización social de las IVE. Por su parte, los sectores conservadores que históricamente se dieron otras estrategias ante los avances de derechos de las mujeres, como la judicialización ${ }^{45}$, también salieron a las calles y participaron en múltiples acciones públicas.

Estas instancias formaron parte de un proceso democrático de debate inédito, que encontró su cauce por las vías institucionales al tratarse en el 2018 por primera vez en el Congreso un proyecto que autorizaba la IVE. En este sentido la legalización de la IVE, en definitiva, abarcó dos ciclos de exposiciones en comisiones celebrados en 2018 y 2020 y cuatro largas jornadas de debate en el seno de las dos cámaras. ${ }^{46}$

Si bien los procesos sociopolíticos que conduce al reconocimiento de derechos son múltiples y complejos, nos detendremos a considerar el comportamiento los votos de diputado/as y senador/as en la ley de la IVE para una aproximación a la cuestión del impacto de la ley de paridad en esta materia.

\section{VI.1 Análisis de las votaciones de la legalización de la IVE en la Cámara de Diputados}

En el año 2018 el proyecto de ley de IVE obtuvo media sanción en la Cámara de Diputados con 129 votos a favor, frente a 125 en contra, para luego ser rechazada por Senadores.

En el año 2020, cuando finalmente se aprobó el proyecto presentado por el Poder Ejecutivo, los votos afirmativos no

\footnotetext{
45 Al respecto recomendamos la lectura de Cecilia GEBRUERS, Cecilia y GHERARDI, Natalia (2015). El aborto legal en Argentina. La justicia después de la sentencia de la Corte Suprema de Justicia en el caso F.A.L., Buenos Aires, CEDES y ELA.

46 Cabe resaltar que la aprobación de la ley en año 2020 se produce no solo luego de la renovación parcial en la conformación de las Cámaras, sino también de la elección presidencial de Alberto Fernández, quien abiertamente se posicionó a favor de la despenalización en su campaña política
} 
variaron sustancialmente (131 votos afirmativos) sin embargo, disminuyeron los votos en contra a 117.

En ese marco cabe resaltar que, de los 131 votos afirmativos, 62 correspondieron a la votación de diputadas mujeres (equivalente al 47,32\% del total de votos afirmativos) mientras que 69 a la votación de diputados varones (lo que equivale el $52 \%$ del total de votos afirmativos). En definitiva, el apoyo a la ley ha sido paritaria en términos de género.

Por el contrario, los votos negativos (117) cuentan con una marcada representación masculina: el $60,68 \%$ de la totalidad de votos en contra de la aprobación de la ley, fueron votos emitidos por varones, lo que corresponde a 71 diputados, mientras que solo 46 diputadas mujeres, votaron por su rechazo.

En ese contexto, resulta interesante analizar el comportamiento de quienes participaron de ambas votaciones, es decir aquellas diputadas y diputados que votaron en el proyecto de ley de IVE del año 2018 como en el proyecto de ley de IVE del año 2020. De la totalidad de los votos afirmativos obtenidos en el año 2020 (131), 54 integrantes de la cámara bajan, 31 diputados varones y 22 diputadas mujeres ya habían votado a favor del primer proyecto de IVE (2018). Solo una diputada que participó en ambas votaciones, cambió su votación desde el rechazo a la aprobación: la diputada Flavia Morales ${ }^{47}$. En su exposición del año 2020, justificó el cambio de su postura principalmente en la representatividad del colectivo de mujeres y la necesidad de regulación, más allá de sus apreciaciones personales. De esta manera, relata un proceso reflexivo que comenzó con el tratamiento del proyecto de ley de IVE del año 2018 y que se potenció con la crisis por la pandemia de COVID

\footnotetext{
47 Diputada por el período 2017-2021 en representación de la provincia Misiones por el Frente de la Concordia Misionero. A raíz de su cambio de posición, fue amenazada públicamente por la Subsecretaria de Culto de la provincia Rossana Barrios quien pertenece al mismo partido lo que demuestra la tranversalidad del debate en relación a las identificaciones partidarias. Véase: http://www.laizquierdadiario.com/Misiones-Subsecretaria-de-Culto-anti-derechosamenaza-a-diputada-que-voto-a-favor-del-aborto
} 
2019. En definitiva, sus palabras reflejan una comprensión de su mandato como representante, en el sentido que debe responder a la gran demanda social por la despenalización:

En particular, más allá de que me toca hablar como legisladora, lo hago como mujer. Creo que de las numerosas exposiciones de especialistas que hemos escuchado -no me refiero exclusivamente a las de esta semana sino a todas las que se presentaron desde el 2018, año en que se comenzó a tratar el proyecto- se desprende claramente la necesidad de que exista una regulación y el Estado debe estar allí presente. (...) Desde la votación del año 2018 -mi primer año como legisladora- hasta boy, he reflexionado $y$ he analizado, pero acá no se trata de hablar en primera persona. (...) No se trata de nosotras, se trata de los otros. He escuchado, he caminado y debo decir que no se trata de lo que yo piense sino de lo que está sucediendo afuera. Estas prácticas clandestinas siguieron sucediendo en pandemia y la verdad es que eso ba becho que reflexione $y$ que analice en profundidad ese tema. No mi posición personal, sino lo que uno escucha en el territorio ${ }^{48}$

En definitiva, sin cambios significativos de posición, la aprobación en el recinto de Diputados en el 2020 (con 131) fue traccionada fundamentalmente por $77^{49}$ diputadas/os que votaron por primera vez y lo hicieron a favor, 35 varones $\mathrm{y}$ 34 mujeres. De estos 77 diputados/as, 69 fueron elegidos/as en vigencia de la ley de paridad de género. Asimismo 7 - 2 diputados y 5 diputadas $^{50}$ - participaron por primera vez en la votación cubriendo un mandato ya en ejercicio.

\footnotetext{
48 Exposición disponible en: https://www4.hcdn.gob.ar/sesionesxml/provisorias/138-17.htm

49 En este recuento, no se contempla el caso del Diputado por Ciudad Autónoma de Buenos Aires, De la Madrid, Álvaro Héctor, toda vez que no figura su voto en el listado oficial de votación del año 2018. Por lo cual, se desconoce su participación en dicho año, pese a que su mandato legislativo está previsto para el periodo 2017-2021 conforme la página oficial de la Cámara de Diputados. Véase (acá poner el link con el listado de la votación) (acá poner el link con el periodo de ese diputado)

50 BERNAZZA, Claudia Alicia del Frente de todos por la provincia de Buenos Aires; CÁCERES, Adriana Cintia,del PRO por la provincia de Buenos Aires; Figueroa, Alcira Elsa del
} 
En este contexto, resulta llamativo analizar nuevamente la composición del voto que rechaza el proyecto la relación al cambio de integración. De los/as 117 diputados/as que en 2020 votaron en contra, 72 (30 diputadas y 42 diputados) ya había participado en la votación del año 2018. Por consiguiente, $45^{51}$ votos de los 117 en contra corresponden a legisladoras/es que se posicionaron por primera vez. De estos nuevos integrantes, 15 fueron diputadas mujeres mientras que el doble, 30 varones.

En los votos en contra hay que considerar que 5 diputados/as cambiaron su voto de haber acompañado el proyecto en el año 2018, a estar contra de la ley de IVE en el año 2020: las diputadas Ayala, Aida Beatriz Máxima Brambilla, Sofía Reyes, Roxana Nahir y el diputado Stefani, Héctor Antonio. Resulta interesante que el único varón en esta categoría fue también el único de los expositores que habló en el debate parlamentario para justificar su cambio de opinión. En ese sentido, sus palabras tuvieron resonancia pública, toda vez que intentando apelar a un argumento sensibilizador, el diputado justificó su actual rechazo a la ley, en un supuesto arrepentimiento de abortar que, en su oportunidad, decidiera la madre de un jugador de fútbol reconocido en el país, es decir, valorando a la mujer que decidió llevar adelante la gestación por su carácter instrumental:

Frente de todos por la provincia de Salta; MARZIOTTA, María Gisela del Frente de todos por la Ciudad Autónoma de Buenos Aires y SCHWINDT, María Liliana del Frente de todos por la provincia de Buenos Aires.

51 En este recuento, no se contempla el caso del Diputado por Santiago del Estero Herrera, Bernardo José, toda vez que no figura su voto en el listado oficial de votación del año 2018. Por lo cual, se desconoce su participación en dicho año, pese a que su mandato legislativo está previsto para el periodo 2017-2021 conforme la página oficial de la Cámara de Diputados. Véase (acá poner el link con el listado de la votación) (acá poner el link con el periodo de ese diputado).

Por otra parte, a los fines del cómputo, se consideraron los votos de Hector Fernandez y Claudia Marquez , como primera participación toda vez que su ingreso se dio en el año 2019, en reemplazo de Fernando Espinoza y Martin Llaryora respectivamente. Cabe resaltar que Espinoza en el 2018 votó a favor del proyecto de ley de IVE, mientras que LLaryora en contra. 
Mónica continuó su vida, estudió, formó una familia y está orgullosa de su hijo. Su hijo es Fernando Cavenaghi. Yo soy de Boca y él nos hizo varios goles, así que lo recuerdo bien. Es uno de los futbolistas goleadores de River Plate. Mónica eligió la vida con convicción, y esa convicción de elegir la vida es la que debería alentarnos a encontrar un punto que dé satisfacción a las dos vidas ${ }^{52}$.

Sin que hayan manifestado en el recinto las razones del cambio en el sentido de su voto, lo cierto es todas las diputadas que lo hicieron pertenecen a la alianza Cambiemos que se encontraba al poder en el año 2018, en tanto que el 2020, formaban parte del bloque opositor al gobierno nacional que presentó el proyecto.

Por otro lado, la única abstención que había obtenido el proyecto de ley en el año 2018, por parte de la diputada por la Provincia de Córdoba, Alejandra María Vigo, derivó en un voto negativo en el 2020. La diputada Vigo expuso en ambos debates parlamentarios. En esta segunda oportunidad, y mediante una exposición contradictoria, fundó su rechazó en la presentación de un proyecto propio del bloque que contemplaba la despenalización más no la legalización, por entender que el aborto no es un derecho, ni tiene relación con la autonomía ni la salud sexual y reproductiva de las mujeres. Por el contrario, refuerza la noción de maternidad e información como elementos que deben ser tenidos en cuenta a la hora de resolver sobre las IVE.

Mi experiencia, como mujer y militante, me indica que las mujeres no hacemos abortos como ejercicio de ninguna clase de libertad, que difícilmente podamos decidir que sí elegimos abortar. Entiendo que, en general, las mujeres llegan a tomar esa decisión porque el embarazo se les hace insostenible. No queremos que sigan muriendo más mujeres, pero legalizar el aborto, hacerlo libre en cualquier situación, no es la respuesta y tampoco debe

52 Exposición del diputado Héctor Antonio Stefani disponible en: https://www4.hcdn.gob. ar/sesionesxml/provisorias/138-17.htm 
ser la salida a una relación frustrada. La mejor inversión para prevenir el embarazo no deseado y acompañar a las mujeres de menos recursos es la prevención y la asistencia en esa situación, para que se valorice la maternidad en la realidad y no solo en el discurso, para que el Estado asegure la información a las mujeres, a las parejas y las familias, para que accedan a ella a la hora de tomar decisiones. ${ }^{53}$

En este contexto, es necesario resaltar que esta fue la exposición representativa de los 4 diputados y diputadas del bloque "Córdoba federal", partido al cual pertenece el gobernador de la provincia de Córdoba, esposo de la diputada ${ }^{54}$. El 72,22\% de los/as diputados/as de esta provincia votaron en contra, por lo cual Córdoba se encuentra dentro de las 6 jurisdicciones con más de un $70 \%$ de diputados/as que votaron en contra de la legalidad de las $\mathrm{IVE}^{55}$.

Los obstáculos que persisten para ejercicio de la función política en igualdad de condiciones por razones de género quedaron de manifiesto en el debate. La violencia contra las mujeres en política ${ }^{56}$ constituye un grave obstáculo que nos impide la plena participación en puestos de toma de decisión

53 Exposición de la diputada Vigo disponible en: https://www4.hcdn.gob.ar/sesionesxml/ provisorias/138-17.htm

54 Hacer alguna referencia a Schiaretti de la cantidad de año para que quede claro que era el gobernador al momento de la votación.

55 De este grupo se destacan también las provincias de Formosa, con un 100\% de diputados/as votaron en contra; las provincias de las provincias de Santiago del Estero, Chaco y Corrientes con un $85,71 \%$ de los/as diputados/as que rechazaron la ley, así como la provincia de la Rioja con un $80 \%$. Cabe advertir que atento el sistema de distribución de bancas por distrito, la cantidad nominal de diputados/as, varía por provincia.

56 La Ley Modelo de Violencia Política de la OEA define en su art. 3 que: “Debe entenderse por violencia política contra las mujeres cualquier acción, conducta u omisión, realizada de forma directa 0 a través de terceros que, basada en su género, cause daño o sufrimiento a una o varias mujeres, y que tenga por objeto o por resultado menoscabar o anular el reconocimiento, goce 0 ejercicio de sus derechos políticos. La violencia política contra las mujeres puede incluir entre otras, violencia física, sexual, psicológica, moral, económica 0 simbólica". 
y refuerza roles tradicionales de género ${ }^{57}$. La diputada Jimena López así lo expuso:

Por favor, a los varones de la política, no llamen más a las compañeras diciéndoles que es probable que pierdan su carrera política. Las cosas no funcionan así. Estamos profundamente convencidas de lo que vamos a votar hoy. Profundamente convencidas. ${ }^{58}$

\section{VI.2 Análisis de las votaciones de la legalización de la IVE en la Cámara de Senadores}

Como se señaló anteriormente, la ley de paridad no tuvo como impacto una modificación de la composición por género del Senado del año 2020. Pero los números nos muestran que tanto en el año 2018 al año 2020, el voto femenino tuvo un marcado peso en apoyo a la legalización de las IVE. En efecto, en el año 2018 el proyecto de ley de IVE obtuvo 31 votos a favor, contra 38 en contra. El voto a favor estaba compuesto por 14 senadoras y 17 senadores, mientras que el de rechazo por 14 senadoras y 24 senadores. Si tenemos en cuenta la cantidad de mujeres que ocupaban banca en la Cámara en esa oportunidad, podemos observar que el voto de las mujeres estaba bastante repartido: el 46,66\% de las senadoras votaron a favor y el mismo número en contra, mientras que el $6,66 \%$ restante correspondió a dos senadoras que se abstuvieron de votar.

Ahora bien, en el año 2020 la situación fue considerablemente distinta, toda vez que de los 38 votos a favor 19 fueron de mujeres senadoras y 19 de varones senadores. No sólo que se mostró una notable paridad en el voto afirmativo, sino que, si

\footnotetext{
57 Véase MARTELOTTE Lucía (2018). Violencia política contra las mujeres en Argentina: experiencias en primera. ELA, Equipo Latinoamericano de Justicia y Género. Disponible en: http://www.ela.org.ar/a2/index.cfm?muestra\&aplicacion=APP187\&cnl=15\&opc=49\&codcontenido $=3229 \&$ plcontampl $=43$

58 Exposición de la diputada Jimena López disponible en: https://www4.hcdn.gob.ar/ sesionesxml/provisorias/138-17.htm
} 
analizamos nuevamente a la luz de la cantidad de mujeres que ocupaban banca, observamos que la proporción de senadoras que apoyaron la ley aumentó considerablemente: del 46,66\% al $67,85 \%$.

Por su parte, el voto en contra de la legalización de las IVE tuvo una amplia representación masculina tanto en la votación del año 2018 como la del 2020. En efecto, el proyecto de ley de IVE del año 2018 obtuvo un total de 38 votos que lograron su rechazo, de los cuales 24 fueron varones y 14 mujeres. Lo que en proporción a la cantidad de varones que ocupaban bancas, se traduce en un $57,14 \%$. En el año 2020, la ley de IVE contó con 29 votos en contra, consistentes en 21 varones senadores y solo 8 mujeres. Es decir que el $72 \%$ de los votos en contra, fueron masculinos. En el 2018, este número fue de $63 \%$.

Si consideramos el total de senadores varones, $47,72 \%$ votaron en contra de la ley en el 2020. Si bien hay una disminución de la proporción de senadores varones que votaron contra la ley, es necesario recordar que el número de varones ocupando bancas en el Senado aumentó y, principalmente, que 3 de las 4 ausencias a la votación, correspondieron a 3 senadores varones que en el año 2018 votaron en contra ${ }^{59}$.

En ese orden de ideas, es dable señalar también que de los 68 senadores y senadoras que votaron en el año 2020 sobre la IVE, 48 se encontraban en ejercicio de funciones en oportunidad de debatirse el proyecto de ley de IVE del año 2018. Es interesante señalar que, la mayoría de los y las senadoras que participaron en ambas votaciones mantuvieron su posición, salvo en 4 personas. En ese sentido, las posiciones que se modificaron fueron las de las senadoras Crexell, Garcia Larraburu y Snopek, mientras que la senadora Catalfamo, que se ausentó en el año 2018, votó a favor de la ley de IVE en el año 2020. La

59 Esto son los Senadores: Carlos Menem, Adolfo Rodriguez Saa y José Jorge Alperovich. Destacamos este último por encontrarse de licencia en virtud de una denuncia de abuso sexual por parte de una empleada de la Cámara. 
senadora Snopek, quién votase en contra del proyecto de ley de IVE en el año 2018, se abstuvo en el año 2020, en tanto la senadora Crexell, que se abstuviese en de votar en 2018, votó a favor de la ley de IVE en el año 2020. Por su parte, la única senadora que cambió claramente su votación fue la senadora García Larraburu, en función de lo que explicase como un proceso reflexivo y personal de deconstrucción. Por ello, si bien en oportunidad del tratamiento del proyecto de ley de IVE del año 2018 votó en contra, en el año 2020 apoyó la legalización de las IVE. En su exposición se posiciona claramente como mujer que conoce y experimenta las consecuencias de los estereotipos de género una sociedad patriarcal:

(...) muchas de las mujeres que estamos aquí, en el recinto, que somos senadoras, somos parte de una generación bisagra. Nos criamos con parámetros del deber ser. Lo que era correcto, lo que se esperaba de nosotras, lo que era legítimo, como mujeres, como madres. Porque la maternidad siempre estuvo asociada a la condición de mujer, lamentablemente. A las que pudimos estudiar, hacer una carrera, se nos exigió aún más, mucho más que a nuestros pares varones. Teníamos que demostrar que éramos aptas, que éramos merecedoras. En toda nuestra vida siempre, siempre, rendimos examen ante la mirada masculina de la sociedad y la mirada del poder. A todas se nos impuso la noción del sacrificio personal. Siempre para satisfacer los estándares preestablecidos. A todas nos juzgan. Todas, en mayor o menor medida, fuimos víctimas de un sistema creado por y para hombres. Ahora lo vemos y le ponemos nombre. Esa normalidad es el patriarcado. Ahora también sabemos que ese proceso reflexivo en el que estructuramos nuestro comportamiento de manera permanente se llama deconstrucción. No es fácil, señora presidenta, deconstruirse. Tambalean las estructuras, aquello que considerábamos firme y sólido. De repente, estamos ahí, ante el abismo de lo nuevo por crear. (...) 
Hace aproximadamente dos años, señora presidenta, yo me encontraba en este recinto sosteniendo una posición diferente a la de hoy. Las cosas cambiaron; otras no cambiaron tanto. Aprendí mucho en estos dos años y siento que haber transitado por los dos pensamientos y emociones respecto de esta ley me da una plusvalía para entenderla desde un lugar más amplio e integral; pero, sobre todo, señora presidenta, de más amor y más empatía. Soy la misma senadora que, en este tiempo, decidió seguir escuchando, escuchando a todas las partes, analizando diferentes situaciones, recibiendo diferentes testimonios; pero, sobre todo, señora presidenta, con un profundo respeto al que piensa distinto.

Mi voto, señora presidenta, es por una mujer libre, que pueda actuar, que pueda decidir según su propia conciencia, sin que nadie, nunca más, le diga lo que tiene que hacer con su propio cuerpo. Mi voto, señora presidenta, es un voto deconstruido; es un voto afirmativo. ${ }^{60}$

De la totalidad de los votos emitidos, 14 fueron de senadores y 6 de senadoras nuevos que ocuparon banca luego del $2018^{61}$ que se expidieron por primera vez al respecto de la legalidad de las IVE. Estos 20 nuevos votos fueron 15 a favor de la ley mientras que 5 en contra. Respecto a los 5 votos en contra, cabe aclarar que 4 fueron de senadores varones, mientras sólo 1 de una senadora mujer, mientras que los 15 a favor, correspondían a 10 senadores varones y 5 mujeres. En otras palabras, de las 6 senadoras mujeres que, habiendo ingresado al Congreso luego de las elecciones del año 2019, por primera vez votaban sobre las IVE, el 83,33\% apoyó la ley.

60 Exposición de la senadora García Larraburu en la Sesión Especial Período 138, $28^{a}$ Reunión, 23a Sesión Especial - 29 y 30 de Diciembre De 2020. Versión taquigráfica disponible en: https://www.senado.gob.ar/bundles/senadomicrositios/pdf/despenalizacionaborto/29_12_2020.pdf

61 Este número no contempla a quienes renovaron mandato, sino quienes ingresaron a la Cámara mediante las elecciones del año 2019, así como quienes suplantaron a senadores/as que hubiesen renunciado en el periodo 2018-2020. 
En sus exposiciones manifestaron su representación como mujeres y el proceso de transformación sociocultural.

(...) quiero hacer mías, y quiero poner en este Parlamento de la Nación, las voces de todas esas mujeres que están a lo largo y ancho del país, que están en las plazas, como les decía; pero también las de nuestras mujeres históricas, de las que nos marcaron el camino de esta lucha feminista, de nuestras ancestras. Y, principalmente, señora presidenta, de aquellas mujeres a las que el Estado no pudo llegar, a las que no llegamos a acompañar, a las que hoy no tienen voz porque hoy no están entre nosotros y entre nosotras. Una vez más nos toca estar acá, en este recinto de la Nación, para hacer cumplir la ampliación de derechos (...) Yo estuve en 2018 acá, afuera. Vine con mis compañeras de militancia de Tierra del Fuego, cuando fue la votación en Diputados. Lamentablemente, en el Senado no tuvimos el acompañamiento. Pero sé lo que es estar en esa marea verde. Sé lo que es estar con esas mismas ansias y ese mismo amor que hoy rodea a este Senado de la Nación (...) (Senadora Duran, debate del día 29/12/2020) ${ }^{62}$

Como senadora, siento y pienso que tenemos una deuda histórica; una deuda histórica con la conquista y los derechos de las mujeres argentinas. Digo esto, porque en la historia del protagonismo de las mujeres en nuestro país, nadie nos regaló nada. Todo lo que conseguimos lo hicimos con lucha, con unidad, con consecuencia, con compromiso, anteponiendo siempre, por sobre todas las cosas y antes que nada, el camino de la verdad y reafirmando el compromiso con los derechos que nos asisten (...) Estos jóvenes que hoy nos acompañan, y que han asumido su compromiso en las calles del país, son los que han nacido en democracia, los que han vivido de las conquistas que he señalado anteriormente, y los que

62 Exposición de la senadora Duran en la Sesión Especial Período 138 $28^{a}$ Reunión, $23^{a}$ Sesión Especial - 29 y 30 de Diciembre De 2020. Versión taquigráfica disponible en: https:// www.senado.gob.ar/bundles/senadomicrositios/pdf/despenalizacion-aborto/29_12_2020.pdf 
hoy reclaman más conquistas porque tienen la decisión de participar en la construcción de un país con menos exclusión, con más igualdades y con más derechos. Y tienen la decisión de asegurar este lugar que a las mujeres nos ha costado tanto alcanzar (...) (Senadora Gimenez, debate del día 29/12/2020) ${ }^{63}$

Con gran emoción debo decirles que siento en mi piel la lucha de cada una de las mujeres, de cada una de las "colectivas", de la Comisión por el Derecho al Aborto y de la gente de la campaña. Siento en mi piel la emoción de acordarme de Evita, de Cristina, que nos dieron el voto y la jubilación de la ama de casa. Siento en mi piel la emoción de cada una de las que perdieron la vida, de las mutiladas, de las criminalizadas, de las niñas violadas, de los niños huérfanos. Siento la gran emoción de cada una de las pibas, las jóvenes y viejas que están afuera, que están luchando, que están dándonos fuerza para esta ley salga. Siento gran emoción por toda la descendencia de todas nosotras, de las que fueron, de las que están afuera y de las que estamos adentro. Por todas ellas, señor presidente: ique sea ley! (Senadora Sapag, debate del día 29/12/2020) ${ }^{64}$

En conclusión, si bien la ley de paridad de género en su reciente implementación no tuvo impacto en la conformación de la Cámara de Senadores, se puede observar una marcada tendencia del voto femenino hacia el apoyo a la legalización de las IVE. Por lo tanto, el aumento de la representatividad de las mujeres y la disminución en la participación masculina, donde se expresó mayoritariamente la resistencia a esta ley, muestra la importancia de garantizar la paridad en la participación política

63 Exposición de la senadora Gimenez en la Sesión Especial Período 138ํㅜ $28^{\text {a }}$ Reunión, $23^{\text {a }}$ Sesión Especial - 29 y 30 de Diciembre De 2020. Versión taquigráfica disponible en: https:// www.senado.gob.ar/bundles/senadomicrositios/pdf/despenalizacion-aborto/29_12_2020.pdf 64 Exposición de la senadora Sapag en la Sesión Especial Período 138을 $28^{\mathrm{a}}$ Reunión, $23^{\mathrm{a}}$ Sesión Especial - 29 y 30 de Diciembre De 2020. Versión taquigráfica disponible en: https:// www.senado.gob.ar/bundles/senadomicrositios/pdf/despenalizacion-aborto/29_12_2020.pdf 
especialmente cuando se tratan de temas en las que tienen una incidencia directa las vivencias y trayectorias de mujeres y otras personas con capacidad de gestar.

\section{Reflexiones finales}

El proceso institucional por la legalización de IVE permite advertir el impulso clave de la participación de mujeres en la toma de decisiones de políticas públicas vinculadas al reconocimiento de los derechos sexuales y reproductivas de las personas con capacidad de gestar.

La participación en política institucional que habilitan medidas como la ley de paridad, como sucedáneo del avance de la participación de las mujeres en distintas esferas públicas, auguran ser los comienzos de un proceso de transformación de la exclusión política y cultural hacia la ampliación de derechos. Sin embargo, este tipo de medidas deben ser implementadas como un punto de partida y no ejecutadas como techos a la participación de los grupos históricamente desaventajados.

Las mujeres, y otras identidades, hemos sido consideradas extranjeras en la política a raíz de supuestos roles fundados en una pretensa naturaleza que sólo escondió los entramados de poder de las culturas occidentales capitalistas heteropatriarcales. Por ello, la representación de nuestras voces en la toma de decisiones es una condición necesaria para la efectiva vigencia de nuestros derechos y la representación de nuestros intereses, permitiendo una democracia más legítima para toda la ciudadanía

En este sentido, si bien el sistema de paridad en las conformaciones de las listas de candidatos y candidatas, son herramientas imprescindibles para el acceso de las mujeres al proceso político, las medidas que el Estado deben tomar para comprometerse con la igualdad no pueden - ni deben - agotarse en ellas. Sostener lo contrario implicaría interpretar las acciones afirmativas desde el prisma de una igualdad formal ineficaz. 
Muchas son las transformaciones necesarias para que las mujeres efectivamente accedamos y participemos en las esferas públicas en igualdad de condiciones, desde las redistribuciones de tareas doméstica y la socialización de los cuidados, hasta los cambios necesarios para prevenir y erradicar las violencias. La desigualdad de género, la violencia de género y la violencia hacia las mujeres en política están estrechamente vinculadas, tal como lo demuestra el hecho de que el mayor acceso de mujeres a puestos de toma de decisiones, aumentan las denuncias de casos de acoso y violencia en el ámbito político.

Para alcanzar la igualdad, la ciudadanía activa y participativa de todas las personas, y de esta manera una verdadera democracia, es imprescindible y urgente que llevemos adelante cambios radicales en nuestras vidas personales. Siguiendo a Pateman (1990) ${ }^{65}$ la vida personal y la política están íntimamente relacionadas:

La creación de una vida personal y sexual libre e igualitaria es el cambio más difícil de lograr de todos los que se requieren para construir una sociedad verdaderamente democrática, precisamente porque no se trata de algo alejado de la vida cotidiana y que pueda ser defendido con lemas abstractos, mientras que la vida y la subordinación de las mujeres transcurren como siempre. Los ideales democráticos y las políticas de la democracia se deben llevar a la práctica en la cocina, la habitación de los niños y la recamara matrimonial (pág. 19)

En este sentido, en contextos de desigualdad como los que vivimos, las IVE implican la posibilidad de que, quienes tenemos la capacidad de gestar, no quedemos enmarcadas en términos biológicos a destinos no deseados y se nos infantilice en nuestra capacidad de tomar decisiones. La legalidad de las IVE va más allá de la posibilidad de interrumpir un embarazo, nos aproxima al reconcomiendo pleno de nuestro derecho de

65 PATERMAN, Carole y SEFCHOVICH (1990). Feminismo y democracia. Debate Feminista, 1. https://doi.org/https://doi.org/10.22201/cieg.01889478p.1990.1.1848 
armar nuestros destinos, tomar nuestras decisiones, en definitiva, diseñar nuestro propio plan de vida. Para ello, la experiencia atravesada por las vivencias de nuestros cuerpos, necesitan tener voz en los lugares de toma de decisiones, en los lugares de poder institucional. Medidas como la paridad en las elecciones parlamentarias como las legalidades de las IVE se encuentran íntimamente imbricadas en la medida que nos permiten diseñar el escenario donde impulsar una vida personal y sexual libre e igualitaria. De cuerpos presentes, en eso estamos. 